\title{
Tatuajes y perforaciones en adolescentes
}

\author{
María Luisa Pérez-Cotapos S , María Laura Cossio $\mathbf{T}^{2}$. \\ Tattooing and piercing in teenagers
}

The presence of mutilations in the form of tattooing and body piercing is becoming increasingly common in adolescents, a practice that is not free of risk. Reported complications include local infections, bleeding, tearing, hypersensitivity reactions, transfusion-transmitted diseases (hepatitis B virus, hepatitis C virus, HIV, syphilis), Chagas' disease and infective endocarditis. On the other hand, several studies have demonstrated an association between body modifications and high-risk behavior in adolescents, as alcohol or drug abuse, cigarette smoking, violence and schooling problems. There is also an association with depression, suicide, eating disorders and other psychophysiologic disorders. This is a review of body modifications in adolescents, emphasizing in the risks, complications and motivations of this practice (Rev Méd Chile 2006; 134: 1322-29).

(Key words: Body piercing; Mental disorders; Psychophysiologic disorders; Tattooing)

Recibido el 6 de septiembre, 2005. Aceptado el 17 de marzo, 2006.

${ }^{1}$ Unidad Docente Asociada de Dermatología, Pontificia Universidad Católica de Chile. ${ }^{2}$ Escuela de Medicina, Pontificia Universidad Católica de Chile.

L a modificación del aspecto externo es una característica humana y universal, que incluye joyas, vestimentas, peinados y métodos más inusuales, como las mutilaciones del cuerpo humano. Cualquier mutilación implica cortar, cercenar o lesionar de forma permanente una parte del cuerpo, entre las que se distinguen las deformaciones esqueléticas, dentarias, circuncisión, ablación del clítoris, escarificación, tatuajes y perforaciones o piercings. Estas prácticas datan desde el neolítico en lo que se refiere a tatuajes; y se conocen ejemplos de los indígenas americanos de la era precolombina con perforaciones ${ }^{1,2}$. En los últimos años han aumentado en la sociedad occidental, especialmente entre los adolescentes.

Correspondencia a: Dra. María Luisa Pérez-Cotapos S. UDA Dermatología Pontificia Universidad Católica de Chile, Centro Médico San Joaquín. Av. Vicuña Mackenna 4686. Fono: 3548492. Fax: 5529974. E mail: dermato@med.puc.cl
Se estima que $10 \%$ a $16 \%$ de los jóvenes entre 12 y 18 años, y 3\% a 8\% de la población general tienen tatuajes ${ }^{2-4}$.

Existen estudios epidemiológicos que definen la asociación entre tatuajes y perforaciones, con infección por virus hepatitis $\mathrm{B}$ (VHB), hepatitis C (VHC), VIH y sífilis. Esto ha adquirido importancia en Salud Pública, ya que en muchos países, quienes poseen tatuajes o perforaciones están inhabilitados para donar sangre. Por otra parte, se ha evaluado la asociación entre conductas de riesgo y la presencia de mutilaciones corporales, especialmente en adolescentes.

Otro punto importante son las complicaciones médicas reportadas como consecuencia de tatuajes y perforaciones, entre las que se encuentran infecciones bacterianas, sangrado, desgarros de tejidos, reacciones de hipersensibilidad, cicatrices y lesiones orales y dentales, que motivan la consulta al especialista. 
La adolescencia

Etimológicamente, adolescencia significa padecimiento, que implica la tarea de encontrarse a sí mismo. Desde el punto de vista físico, comesponde a un periodo de cambios y crecimiento rápido que va desde los 11 a los 19 años. Además, se producen cambios psicológicos normales, que se manifiestan en el adolescente por la búsqueda de identidad propia, oposición a la autoridad, originalidad, imaginación, narcisismo, cambios bruscos en la confianza en sí mismo, desarreglos emotivos, deseo de conocimiento del mundo y búsqueda de nuevas experiencias.

Sin embargo, estas caractenísticas normales de la adolescencia, pueden volverse patológicas cuando son exageradas. Entre las patologías de la adolescencia se encuentran la inhibición intelectual o inflexión escolar excesiva, los trastomos del estado de ánimo, y la patología de las conductas centradas en el cuerpo, que incluye las modificaciones corporales.

\section{Modificaciones corporales más frecuentes}

Tatuajes. El origen de la palabra tatuaje derivaría de la práctica polinésica de crear un dibujo sobre la piel por medio del golpeteo de un hueso contra otro con el consiguiente sonido «au-tau». En latín, tatuaje significa estigma o marca, asociándose a marginales, incultos y anticristianos. Hoy en día, en cambio, los tatuajes y perforaciones son considerados ornamentos de moda, arte corporal, fijación de la personalidad y atracción sexual, y constituyen una realidad social.

Consisten en la inserción de un pigmento insoluble dentro o debajo de la piel, mediante inyección directa del pigmento con aguja. El pigmento más usado es el carbón (grafito), además de pigmentos biológicos y extractos de plantas y óxidos minerales (ocre). Actualmente se utilizan alrededor de 50 pigmentos, entre los que se encuentran sales metálicas y colorantes sintéticos. La inserción del pigmento en la piel desencadena una respuesta inflamatoria, que se manifiesta como descamación inicial de la epidermis e inflamación de la dermis. El pigmento es fagocitado como cuerpo extraño por macrófagos de la dermis, y posteriormente drena gran parte hacia los ganglios linfáticos, quedando un residuo en los macrófagos ${ }^{1}$ (Figura 1).

Otro tipo de tatuajes son los de henna, también llamados temporales, porque duran aproximadamente dos semanas, y a diferencia de los otros tatuajes, no se utilizan agujas ni otros objetos para perforar la piel. La henna es una planta originaria de India y el norte de África, cuyas hojas son molidas y mezcladas con aceites para formar una pasta que tiñe la piel color café u ocre ${ }^{5}$.

Perforaciones. Se realizan en tejidos blandos como pabellón auricular, labios, lengua, cejas, ombligo u otra parte del cuerpo, mediante agujas o catéteres de distintos calibres, que permiten insertar el elemento ornamental. Éste es generalmente metálico, y puede ser de níquel o plata, aunque los más utilizados actualmente son acero quirúrgico, niobio y titanio ${ }^{1}$ (Figura 2).

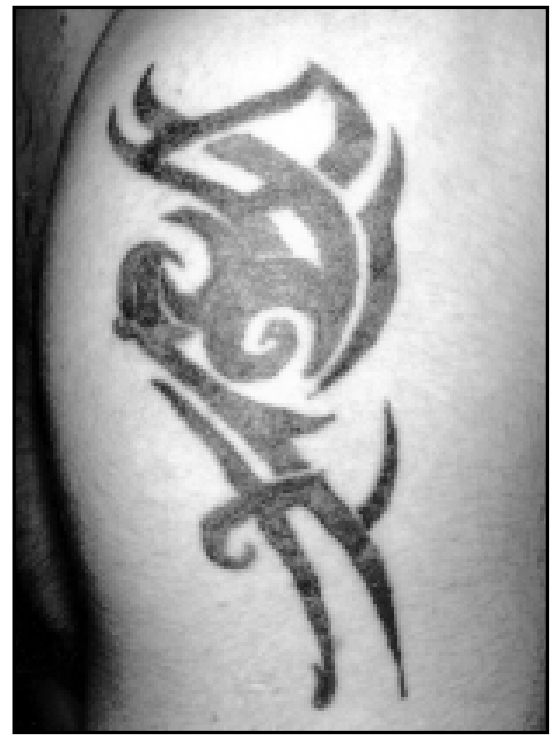

Figura 1. Tatuaje en brazo.

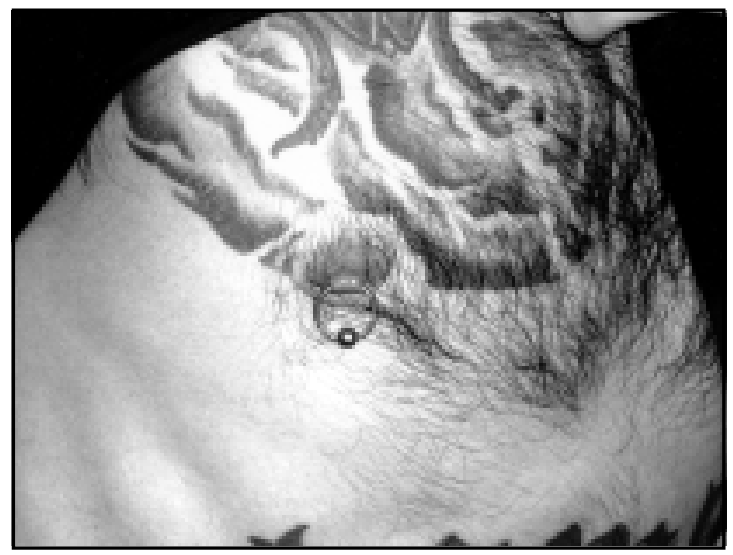

Figura 2. Perforación en pezón y tatuaje en tórax. 
Escarificaciones. Son menos comunes que los tatuajes y perforaciones, y consisten en inferir una quemadura o una incisión en la piel, y luego aplicar un pigmento ${ }^{1}$. Aunque la mayoría de los casos reportados se asocian a patología psiquiátrica, su uso está en aumento entre los adolescentes, y no tardarán en aparecer sus complicaciones médicas 6 .

Diagnóstico diferencial de mutilaciones

Dentro del diagnóstico diferencial de mutilaciones, especialmente escarificaciones, se encuentran las escoriaciones neuróticas. Estas forman parte del grupo de enfermedades psicocutáneas, caracterizadas por lesiones en la piel autoinflingidas en forma habitual y repetitiva. Aunque se trata de una mutilación autoinferida, no es una modificación corporal realizada por motivos estéticos 0 socioculturales, sino más bien una conducta compulsiva descrita principalmente en mujeres entre 20 y 30 años, asociada a trastornos de ansiedad y depresión.

Tatuajes, perforaciones, y enfermedades de transmisión sexual (ETS)

La demanda de glóbulos rojos y otros productos sanguíneos está en aumento, ya que el tratamiento de algunos pacientes requiere transfusiones. La obtención de la sangre se realiza a partir de donantes voluntarios, que antes de ser aceptados deben responder una encuesta destinada a detectar factores de riesgo de ETS. Una vez descartado ese riesgo, entre otros requisitos, se extraen 500 $\mathrm{ml}$ de sangre, que no se transfunden al receptor hasta no someterse a exámenes de laboratorio para virus hepatitis $\mathrm{B}, \mathrm{C}, \mathrm{VIH}$, enfermedad de Chagas y sífilis. El costo de estos exámenes es alto y aumenta constantemente con la implementación de tests más sensibles y específicos, por lo que se han diseñado estrategias para reducirlos, como la encuesta ya mencionada ${ }^{7}$.

Una de las preguntas de la encuesta es si posee un tatuaje, y si lo adquirió dentro de los últimos 12 meses, que se considera como suficiente para descartar una infección en período de ventana7. Esto permite no realizar exámenes a pacientes cuya sangre será rechazada, y con ello reducir costos. El problema surge a raíz del incremento actual del uso de tatuajes, que reduce en forma importante el número de potenciales donantes, por lo que se hace necesario determinar quiénes de los que tienen tatuajes tienen efectivamente mayor riesgo de resultar positivos al estudio de ETS.

Los primeros estudios que evaluaron asociación entre tatuajes y ETS se realizaron en población penitenciaria, donde la prevalencia de ETS era muy alta, y quienes poseían tatuajes eran en su mayoría usuarios de drogas endovenosas, lo que sobreestimaba dicha asociación ${ }^{7}$. Estudios recientes realizados en población general, muestran que la presencia de tatuajes se asocia a mayor prevalencia de infección por VHC y ETS ${ }^{8}$. También se ha encontrado asociación entre mayor número de tatuajes e infección por VHB, y entre tatuajes no realizados por profesionales y resultado positivo para alguna ETS 9 . Otros estudios realizados en usuarios de drogas endovenosas demuestran asociación entre tatuajes adquiridos en prisión e infección por VHB y $\mathrm{VHC}^{10}$.

Según la literatura revisada, la presencia de tatuajes se asocia a ETS, por lo que sería un marcador eficiente (costo-beneficio) en donantes de sangre. Sin embargo, por el gran aumento del uso de tatuajes, definir subgrupos de mayor riesgo podría ser una buena alternativa. Algunos de estos subgrupos podrían ser pacientes que poseen más de un tatuaje, la realización del tatuaje por un no profesional, o la adquisición de éste en la cárcel.

En cuanto a las perforaciones, hay menos datos publicados al respecto, pero se ha encontrado asociación con infección por VIH, VHB y VHC (especialmente este último).

Tatuajes y perforaciones como indicadores de conductas de riesgo en adolescentes

Como los primeros estudios sobre tatuajes y perforaciones se realizaron en población penitenciaria, su asociación con conductas de riesgo como alcoholismo, drogadicción y violencia era incrementada por la alta prevalencia de estas conductas en dicha población.

En la población general, aunque en menor medida, la asociación persiste, especialmente en adolescentes, constituyendo la presencia de tatuajes y perforaciones un indicador visible de posibles conductas de riesgo. Estudios en adolescentes revelan que poseer un tatuaje o perforación implica 
significativamente mayor riesgo de abuso de sustancias, actividad sexual, desórdenes alimentarios y suicidio, al comparar con adolescentes de igual edad sin tatuajes o perforaciones ${ }^{3}$. También se describe mayor consumo de drogas «landas»como tabaco, alcohol y marihuana asociado a menor edad de adquisición de tatuajes o perforaciones; mientras que mayor consumo de drogas «duras» como cocaína, metanfetaminas y ectasis se asocia a mayor número de perforaciones en el cuerpo ${ }^{3}$. Estudios en jóvenes que ingresan al servicio militar confirman la asociación de tatuajes y abuso de alcohol y tabaco ${ }^{11}$; y se estima que en adolescentes entre 14 y 18 años con mutilaciones corporales la frecuencia de abuso de sustancias es 3 veces mayor que en sus pares ${ }^{12}$. Otros estudios realizados en universitarios, asocian la presencia de tatuajes a mayor frecuencia de violencia y problemas académicos $^{4}$.

En cuanto a las características psicosociales de los adolescentes que se realizan tatuajes y perforaciones, ellos perciben menor cercanía afectiva y apoyo de sus padres ${ }^{13}$; y en mujeres, la mayor frecuencia de sentimientos de rabia, agresividad y depresión se correlaciona con mayor número de perforaciones ${ }^{14}$. Además, hay estudios que describen que patologías psiquiátricas como los trastornos de personalidad antisocial y limítrofe (borderline), y el abuso de alcohol y drogas se asocian frecuentemente con la presencia de tatuajes ${ }^{15}$.

Las escarificaciones, a diferencia de los tatuajes y perforaciones, se asocian en la mayoría de los casos a trastornos psiquiátricos como los ya mencionados. También se encuentran este tipo de lesiones en adolescentes mujeres que han sido víctimas de abuso sexual, y se autoinfieren lesiones como una forma de dimpiar» la piel que fue tocada por el abusador ${ }^{16}$.

Complicaciones médicas de tatuajes y perforaciones Perforaciones (Tabla 1). Cerca de $10 \%$ a $20 \%$ de las perforaciones se infectan, siendo los agentes causales más frecuentes el Staphylococcus aureus, Streptococcus grupo A y Pseudomona spp, que pueden ocasionar cuadros infecciosos severos ${ }^{17}$. De hecho, se han descrito numerosos casos de endocarditis bacteriana secundaria a infecciones locales en sitios de perforaciones, especialmente en pacientes con cardiopatías congénitas o daño valvular previo y en los casos de perforaciones en la cavidad oral ${ }^{18,19}$.

También se describen infecciones locales como la de herida operatoria en cirugía laparoscópica, en pacientes con perforaciones en el ombligo; las infecciones mamarias por micobacterias, secundarias a perforaciones en los pezones, que pueden simular una lesión maligna; y los abscesos pericondrales en oreja y nariz ${ }^{1,20-22}$.

Las perforaciones de tejidos blandos también pueden producir desgarros, sangrado, formación de queloides (Figura 3). Estos últimos son más frecuentes en pacientes que se perforan los

\section{Tabla 1. Complicaciones de las perforaciones}

\section{Infecciosas:}

- Locales (infección de herida, abscesos pericondrales)

- Sistémicas (Endocarditis bacteriana)

No infecciosas:

- Desgarros

- Sangrado

- Formación Queloides

- Dermatitis de Contacto alérgica por metales

- Deformidades mucogingivales, pérdida y daño estructuras dentales

- Dificultad para la intubación orotraqueal de urgencia

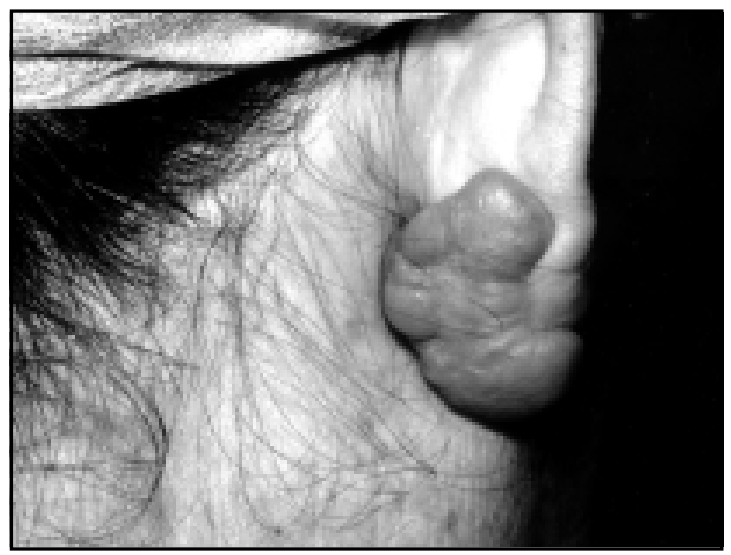

Figura 3. Queloide en lóbulo de la oreja secundario a perforación. 


\section{Tabla 2. Complicaciones de los tatuajes}

\begin{tabular}{|l} 
Infecciosas: \\
- Locales \\
- Bacterianas (S aureus, S grupo A, \\
Pseudomona sp, M tuberculosis) \\
- Virales (herpes, virus papiloma) \\
- Fúngicas \\
- Sistémicas \\
- Endocarditis bacteriana \\
- ETS: hepatitis B, C, VIH, sífilis \\
No infecciosas: \\
- Fotosensibilidad \\
- Reacciones de hipersensibilidad retardada \\
- Reacciones granulomatosas a cuerpo extraño \\
- Reacciones liquenoides \\
- (especialmente pigmento rojo) \\
Aparición de lesiones malignas \\
- Migranoma maligno) \\
- Aparición del pigmento a ganglios vecinos \\
del tatuaje (fenómeno de Koebner) \\
- Dermatitis de contacto alérgica a PPD y otras \\
sustancias (tatuajes de Henna)
\end{tabular}

lóbulos de las orejas después de los 11 años de edad y que tienen antecedentes familiares de queloides ${ }^{23}$, y reacciones alérgicas, especialmente dermatitis de contacto alérgica por metales, que incluso puede ser de tipo granulomatosa ${ }^{24,25}$. De hecho, hay estudios que describen el número de perforaciones como predictor estadísticamente significativo de alergia a metales ${ }^{26}$.

Otras complicaciones de las perforaciones en la cavidad oral son las deformidades mucogingivales ${ }^{27}$, y la dificultad para la intubación orotraqueal de urgencia ${ }^{28}$.

Tatuajes (Tabla 2). Los agentes causales más frecuentes de infecciones bacterianas por inoculación son los mismos descritos para las perforaciones $^{29}$, pero hay casos reportados de infección por Mycobacterium tuberculosis ${ }^{30}$; y también de endocarditis bacteriana secundaria a infección lo$\mathrm{cal}^{31}$. Además se ha descrito infección por virus papiloma e infecciones por hongos en el sitio del tatuaje $^{32}$ (Figura 4).

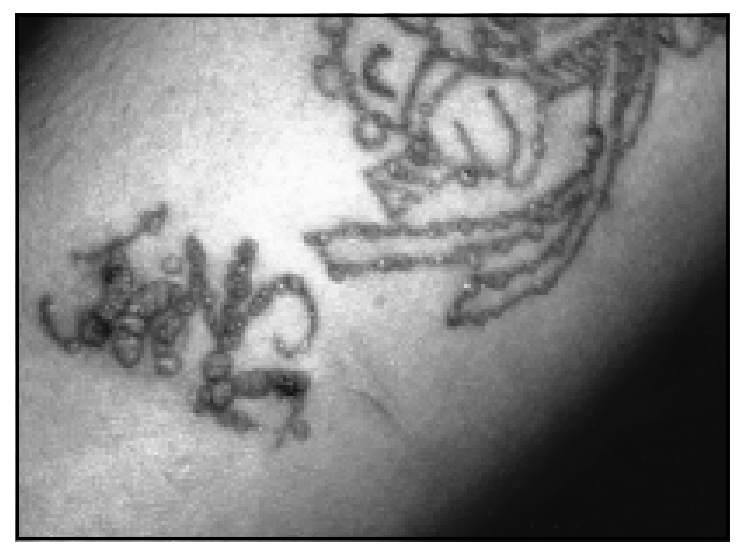

Figura 4. Infección por virus papiloma (verrugas) en tatuaje en brazo.

Las reacciones alérgicas al pigmento insertado en la piel van desde reacciones granulomatosas a cuerpo extraño hasta reacciones liquenoides ${ }^{1}$. El pigmento rojo (sulfato de mercurio y óxido de hierro) es el que más frecuentemente se asocia a hipersensibilidad retardada y reacciones liquenoi$\operatorname{des}^{33}$, aunque estas complicaciones también se observan con otros pigmentos.

En el caso de los tatuajes temporales o de henna, la principal complicación es la dermatitis de contacto alérgica al compuesto parafenilendiamina (PPD) presente en el pigmento de la henna. También es frecuente el uso de tatuajes de henna negro, color que se logra agregando otras sustancias que también pueden producir dermatitis de contacto alérgica, como la goma látex natural ${ }^{34}$.

Se han descrito casos de aparición de lesiones malignas en tatuajes, especialmente melanoma maligno, dificultando su diagnóstico precoz al camuflarse la lesión pigmentaria con el tatuaje ${ }^{35}$. También se han reportado casos de melanoma maligno en que clínicamente se encuentran ganglios pigmentados, pero que no muestran micrometástasis al estudio histopatológico, sino que deben su color a la migración del pigmento de tatuajes ${ }^{36}$.

La lesión en la dermis puede desencadenar también el fenómeno de Koebner, por lo que pacientes con dermatosis latentes pueden presentar reacciones en el sitio del tatuaje ${ }^{37}$. 
Normas sanitarias

La adopción de medidas sanitarias reguladoras sobre quienes realizan tatuajes y perforaciones surge de la preocupación pública por la posibilidad de transmisión de enfermedades cuyo pronóstico es potencialmente grave ${ }^{38}$.

Desde el año 2002 está en vigencia en Chile el «Reglamento de Tatuajes y Prácticas Similares»del Ministerio de Salud. Este reglamento sregula el ejercicio de toda práctica que, con fines cosméticos, consista en la penetración, perforación, corte, escarificación o introducción de pigmentos u objetos en la piel o mucosas de personas; tales como tatuajes o colocación de joyas en la nariz, orejas u otra parte del cuerpo 39 .

Entre los requisitos que deben cumplir los establecimientos se encuentran: superficies de trabajo lavables y limpias, lavamanos, iluminación, sillas, camilla, recipientes para el material cortopunzante e instalaciones para el lavado de materiales. Además, cada establecimiento debe tener un director técnico mayor de edad que acredite ante la autoridad sanitaria que posee conocimientos sobre esterilización, técnica aséptica e higiene.

Respecto a los procedimientos, señala que:

No deben realizarse si la piel o mucosas tienen un proceso infeccioso $\mathrm{u}$ otras lesiones como pústulas, abscesos, acné o dermatitis. Antes de realizar el procedimiento, se debe informar a quien lo recibe, en forma verbal y por escrito, sobre los riesgos, cuidados de la zona afectada, y necesidad de consultar a un médico ante signos de infección, dolor u otra complicación. Todo procedimiento debe realizarse con técnica aséptica (uso de antiséptico en la piel, campo estéril, guantes estériles) y todo el material utilizado debe ser estéril. Los pigmentos usados deben ser no tóxicos y ajustados a la nómina de colorantes permitidos del Ministerio de Salud. Los objetos instalados permanentemente deben ser de material inerte, no tóxico e inoxidable. El material utilizado no desechable debe esterilizarse correctamente. El establecimiento debe verificar que quien se realiza el procedimiento sea mayor de edad, o cuente con una autorización escrita de un representante legal que lo acompañe. La persona que realiza el procedimiento debe ser mayor de edad y estar vacunado contra hepatitis $B$.
Tatuajes profesionales versus artesanales

Los tatuajes y perforaciones profesionales» son aquellos realizados en establecimientos que cumplen con el reglamento del Ministerio de Salud. Los «artesanales» no son solamente aquellos realizados por personas poco expertas (amigos) sino también los realizados por expertos que no cumplen con las normas ya mencionadas.

Un estudio reciente realizado en adolescentes de la región metropolitana de entre 15 y 19 años, reveló que más de $50 \%$ de ellos prefirió realizar sus perforaciones en su domicilio particular, ya sea por sí mismo o por un amigo, y en segundo lugar en una feria artesanal. En este mismo estudio, los adolescentes encuestados refirieron complicaciones médicas de las perforaciones en más de $50 \%$ de los casos, lo que es compatible con la realización de los procedimientos en forma «artesanal $\Downarrow^{\sharp 0}$.

A pesar de los esfuerzos por regularizar estas prácticas, mediante la entrega de información y la vigilancia de los lugares donde se realizan, el cumplimiento de las recomendaciones no es completo, y la suspensión de los programas de control produce aumento del grado de incumplimiento ${ }^{37}$.

Por otra parte, el uso de perforaciones faciales 0 tatuajes en sitios visibles por parte de los médicos y estudiantes de medicina es percibido por los pacientes como inapropiado, afectando su competencia, credibilidad y confianza ${ }^{41}$.

\section{Remoción de tatuajes}

El láser es el método de elección para la remoción de tatuajes, pues permite eliminar en forma selectiva los diferentes pigmentos con bajo riesgo de cicatrices residuales. Sin embargo, se necesitan muchas longitudes de onda para tratar los tatuajes multicolores, por lo que no hay un solo sistema láser que remueva todos los pigmentos disponibles y sus combinaciones.

\section{CONCLUSIONES}

Las modificaciones corporales como tatuajes, perforaciones y escarificaciones son cada vez más frecuentes y más aceptadas entre los adolescentes. La asociación con enfermedades de trans- 
misión sexual varía entre los diferentes estudios, pero la mayoría coinciden en el mayor riesgo de infección por hepatitis B, C y VIH en quienes se realizan tatuajes y perforaciones, especialmente si no es en manos de un profesional. La exclusión de los portadores de tatuajes y perforaciones como donantes de sangre está en discusión debido a la creciente demanda de derivados sanguíneos y a la masificación de estas modificaciones corporales.

Las complicaciones médicas de tatuajes y perforaciones van desde daño local por infección, desgarro, sangrado, reacciones alérgicas y cicatrices, hasta compromiso sistémico como la endocarditis bacteriana. Las perforaciones en la boca representan además una dificultad en la intubación orotraqueal de urgencia.

\section{REFERENCIAS}

1. Chimenos E, Batue I, Velásquez S, García T, Viñals H, Rosewó X. Appearance and culture: oral pathology associated with certain fashions» (tattoos, piercings, etc.). Med Oral 2003; 8: 197-206.

2. Mayers L, Judelson D, Moriarty B, Rundell K. Prevalence of body art (body piercing and tattooning) in university undergraduates and incidence of medical complications. Mayo Clin Proc 2002; 77: 29-34.

3. CARrol ST, RifFenburgh RH, Roberts TA, Myhre EB. Tattoos and body piercings as indicators of adolescent risk-taking behaviors. Pediatrics 2002; 109: 1021-27.

4. RoberTs TA, Ryan SA. Tattooning and high-risk behavior in adolescents. Pediatrics 2002; 110: 1058-63.

5. Neri I, Guareschi E, Savoia F, Patrizi A. Childhood allergic contact dermatitis from henna tattoo. Pediatr Dermatol 2002; 19: 503-5.

6. Armstrong ML, KeLly L. Tattooning, body piercing, and branding are on the rise: perspectives for school nurses. J Sch Nurs 2001; 17: 12-23.

7. Nishioka S, Gyorkos T, McLfan JD. Tattoos and transfusion-transmitted disease risk: implications for the screening of blood donors in Brazil. BJID 2002; 6: 172-80.
Los esfuerzos por educar tanto a tatuadores como a la población general, la vacunación contra el virus hepatitis $B$, la estandarización de las precauciones en los centros donde se realizan tatuajes, el control de calidad por parte de la autoridad sanitaria, y la regulación legal en menores de 18 años, son medidas fundamentales en la prevención de las complicaciones antes descritas.

$\mathrm{Si}$ bien el hallazgo de tatuajes o perforaciones no significan necesariamente presencia de conductas de alto riesgo en un adolescente en particular, los estudios poblacionales muestran mayor frecuencia de estas conductas en adolescentes con modificaciones corporales, lo que debe alertar al clínico a preguntar dirigidamente por este tipo de conductas sin estigmatizar, pues este fenómeno constituye una realidad social.

8. Nishioka S, Gyorkos T, Joseph L, Colet JP, McLean JD. Tattooning and transfusion-transmitted diseases in Brazil: a hospital-based cross-sectional matched study. Eur J Epidemiol 2003; 18: 441-9.

9. Nishioka S, Gyorkos T, Joseph L, Colet JP, McLfan JD. Tattooning and transfusion-transmitted diseases: the role of the tyoe, number and desing of the tattoos, and the conditions in which they were performed. Epidemiol Infect 2002; 128: 6371.

10. Samuel MC, Doherty PM, Bulterys M, Jenison SA. Association between heroin use, needle sharing and tattoos received in prison with hepatitis $B$ and $\mathrm{C}$ positivity among street-recruited injecting drug users in New Mexico, USA. Epidemiol Infect 2001; 127: 475-84.

11. StePHENS MB. Behavioral risks associated with tattooning. Fam Med 2003; 35: 52-4.

12. Brooks TL, Woods ER, Knight JR, Shrier LA. Body modification and substance use in adolescents: is there a link? J Adolesc Health 2003; 32: 44-9.

13. Meland E, Breidabuk HJ, Vik LJ, Ekeland TJ. Teenagers with piercing and tattooning. Tidsskr Nor Laegeforen 2004; 124: 1760-3.

14. CARROL L, ANDERSON R. Body piercing, tattooning, self-esteem, and body investment in adolescent girls. Adolescence 2002; 37: 627-37. 
15. RASPA RF, CuSACK J. Psychiatric implications of tattoos. Am Fam Physician 1990; 41: 1481-6.

16. Cavanaugh RM. Self-induced carving and scarification of the foreams as manifestation of sexual abuse in a 14-year-old adolescent girl. J Pediatric Adolesc Gynecol 2000; 13: 97-8.

17. Guiard-Schmid JB, Picard H, Slama L, Maslo C, Amiel C, Pialoux G, Lebrette MG, Rozenbaum W. Piercing and its infectious complications. A public health issue in France. Presse Med 2000; 29: 1948-56.

18. Dubose J, Pratt JW. Victim of fashion: endocarditis after oral piercing. Curr Surg 2004; 61: 474-7.

19. Raja SG, Shad SK, Dreyfus GD. Body piercing: a rare cause of mitral valve endocarditis. J Heart Valve Dis 2004; 13: 854-6.

20. Friedel JM, Stehli J, Desai M, Granato JE. Infective endocarditis after oral body piercing. Cardiol Rev 2003; 11: 252-5.

21. Jacobs VR, Morrison Je Jr, Paepke S, Kiechle M. Body piercing affecting laparoscopy: perioperative precautions. J Am Assoc Gynecol Laparosc 2004; 11: 537-41.

22. Lfwis CG, WeLus MK, Jennings WC. Mycobacterium fortuitum breast infection following nipple-piercing, mimicking carcinoma. Breast J 2004; 10: 363-5.

23. LANE JE, WALER JL, Davis LS. Relationship between age of ear piercing and keloid formation. Pediatrics 2005; 115: 1312-4.

24. Gold MA, Schorzman CM, Murray PJ, Downs J, Tolentino G. Body piercing practices and attitudes among urban adolescents. J Adolesc Health 2005; 36: 352.e 17-24.

25. Casper C, Groth W, Hunzelmann N. Sarcoidal-type allergic contact granuloma: a rare complication of ear piercing. Am J Dermatopathol 2004; 26: 59-62.

26. EHRLCH A, KuCENIC M, Belsito DV. Role of body piercing in the induction of metal allergies. Am J Contact Dermat 2001; 12: 151-5.

27. Brooks JK, Hooper KA, Reynolds MA. Formation of mucogingival defects associated with intraoral and perioral piercing: case reports. J Am Dent Assoc 2003; 134: 837-43.

28. Kuczkowski KM, Benumof JL. Tongue piercing and obstetric anesthesia: is there cause for concern? J Clin Anesth 2002; 14: 447-8.

29. Handrick W, Nenoff P, Muler $H$, Knofler W. Infections caused by piercing and tattoos: a review. Wien Med Wochenschr 2003; 153: 194-7.

30. Wong HW, TAY YK, Sim CS. Papular eruption on a tattoo: a case of primary inoculation tuberculosis. Australas J Dermatol 2005; 46: 84-7.

31. Dahnert I, Schneider P, Handrick W. Piercing and tattoos in patients with congenital heart disease: is it a problem? Z Kardiol 2004; 93: 618-23.

32. Ammrati CT. What is your diagnosis? Tinea in tattoo. Cutis 2004; 73: 228-32.

33. Mortimer NJ, Chave TA, Johnston GA. Red tattoo reactions. Clin Exp Dermatol 2003; 28: 508-10.

34. Martin JA, Hughes TM, Stone NM. Black henna tattoos: an occult source of natural rubber latex allergy? Contact Dermatitis 2005; 52: 145-6.

35. Soroush V, Gurevitch AW, Peng SK. Malignant melanoma in a tattoo: case report and review of the literature. Cutis 1997; 59: 111-2.

36. Moenrle M, Blaheta HJ, Ruck P. Tattoo pigment mimics positive sentinel lymph node in melanoma. Dermatology 2001; 203: 342-4.

37. ЈАсов CI. Tattoo-associated dermatoses: a case report and review of the literature. Dermatol Surg 2002; 28: 962-5.

38. Arujo M, Kraemer P, Otaíza F. Riesgo de transmisión de infecciones virales a través de tatuajes. Minsal 2001. Disponible en www.minsal.cl

39. Reglamento de Tatuajes y Prácticas Similares. Minsal 2002. Dto. 304/02. Disponible en www.minsal.cl

40. Fuenzalda H, Álvarez E, Martín C. Piercing en un grupo de población escolar santiaguina. Rev Chilena Dermatol 2003; 19: 271-6.

41. Newman AW, Wright SW, Wrenn KD, Bernard A. Should physicians have facial piercings? J Gen Intern Med 2005; 20: 213-8. 